Original Article

\title{
Cardiorespiratory endurance in children with and without cerebral palsy as measured by an ergometer: a case series study
}

\author{
Jee Woon Jung, PhD Candidate, $\mathrm{PT}^{1)}$, Ji- Hea Woo, PhD, $\mathrm{PT}^{2)^{*}}$, Jooyeon Ko, PhD, $\mathrm{PT}^{3)}$, \\ Heesoo Kim, PhD, $\mathrm{OT}^{2}$ \\ 1) Department of Rehabilitation Therapy, Graduate School of Hallym University, Republic of Korea \\ 2) Department of Physical Therapy, Hallym College: Janghak-ri, Dong-myeon, Chuncheon-si, \\ Gangwon-do 200-711, Republic of Korea \\ 3) Department of Physical Therapy, Daegu Health College, Republic of Korea
}

\begin{abstract}
Purpose] This preliminary study aimed to determine the cardiorespiratory endurance of children with cerebral palsy $(\mathrm{CP})$ using a case series study in order to provide the reference data required for interventions appropriate for South Korean CP sufferers, since aerobic ability evaluation and interventions for children with CP are not well recognized in South Korea. [Subjects and Methods] Four children and adolescents with CP GMFCS (Gross Motor Function Classification System) level I and II and two normally developing children (ND) (age: 7-15 years) were studied. Cycle ergometer testing was performed to determine their $\mathrm{VO}_{2}$ peak and RER peak concentrations as well as VE peak and 6MWT distance. [Results] The $\mathrm{VO}_{2}$ peak was lower in subject $\mathrm{E}(\mathrm{CP})$ at 44.5 than in subject $\mathrm{B}$ (ND), and it was lower in subject A (ND) at 22.9 than in subject C (CP). The 6MWT distance was longer in subjects $\mathrm{A}$ and $\mathrm{B}$ (ND) than in age-matched CP subjects. [Conclusion] This case report demonstrates that the cardiorespiratory parameters values of $\mathrm{CP}$ children were similar to those reported previously. Further research is required to evaluate the normative values of $\mathrm{CP}$ and the optimal cardiorespiratory parameters.

Key words: Cardiorespiratory endurance, Ergometer test, Cerebral palsy
\end{abstract}

(This article was submitted Dec. 17, 2014, and was accepted Jan. 31, 2015)

\section{INTRODUCTION}

Cerebral palsy (CP), defined as a nonprogressive injury to the brain, covers numerous neurological conditions, which result in abnormal development of movement and postural control. Injury to the brain typically results in impairments in motor function, such as muscle weakness, spasticity, and decreased selective motor control, which are primary causes of children with $\mathrm{CP}$ limitations in the performance of activities of daily living and participation ${ }^{1)}$. Children with $\mathrm{CP}$ have a decreased level of daily physical activity in comparison to their healthy peers. They do not use their physical reserves sufficiently during the day to achieve optimal levels of daily physical activity ${ }^{2}$. Children with $\mathrm{CP}$ need to maintain a higher level of physical fitness than healthy children in order to maintain the natural growth process as they grow older ${ }^{3)}$.

The peak oxygen uptake $\left(\mathrm{VO}_{2}\right.$ peak), typically used as a measure of aerobic fitness, is lower in children with $\mathrm{CP}$, as has been shown through exercise tests using cycle ergometry

*Corresponding author. Ji-Hea Woo (E-mail: palpation@ empas.com)

(C2015 The Society of Physical Therapy Science. Published by IPEC Inc. This is an open-access article distributed under the terms of the Creative Commons Attribution Non-Commercial No Derivatives (by-ncnd) License $<$ http://creativecommons.org/licenses/by-nc-nd/3.0/>. or a treadmill ${ }^{4,5)}$. The maximum aerobic physical fitness, $\mathrm{VO}_{2}$ peak, is an internationally acknowledged measure of the fitness of the cardiorespiratory system. Three studies ${ }^{4-6)}$ have studied $\mathrm{VO}_{2}$ peak in children and adolescents with $\mathrm{CP}$ during a maximal exercise test. These studies compared $\mathrm{VO}_{2}$ peak to the values observed in normally developing (ND) children and adolesents ${ }^{5,6}$. The most functional and appropriate way to assess $\mathrm{VO}_{2}$ peak in children with $\mathrm{CP}$ who are able to walk independently is a progressive walking or running-based maximal exercise test ${ }^{4,7)}$. Various researchers have developed treadmill walking maximal exercise tests to assess individuals with $\mathrm{CP}$ and to investigate the effectiveness of rehabilitation programs ${ }^{4-6,8-11)}$.

However, these methods limit the generalization of the results to actual daily walking, because a variety of comfortable walking speeds are exhibited by children with different types of $\mathrm{CP}^{5)}$. Therefore, it is important to test children under general conditions that are comparable to daily living conditions. For estimating the maximal aerobic capacity, an adapted cycle ergometer test specifically developed for CP can be used $^{12,13)}$. This aerobic test has the advantage of reducing errors that are produced when walking with diverse patterns. Currently, studies of ergometer aerobic tests ${ }^{14}$ have provided insufficient evidence of their effect ${ }^{12,15)}$; furthermore, no direct cardiorespiratory results have been considered in the aerobic measurements ${ }^{16)}$. Although Unnitan et al. ${ }^{17)}$ studied the effect of uphill walking on children with diplegic 
Table 1. General characteristics of subjects

\begin{tabular}{cccccccc}
\hline & Subjects & Type & GMFCS level & $\begin{array}{c}\text { Gender } \\
\text { (boys: 0, girls: 1) }\end{array}$ & Age (years) & Height (cm) & Weight (kg) \\
\hline \multirow{2}{*}{ ND } & A & - & - & 0 & 12 & 151 & 48 \\
& B & - & - & 1 & 7 & 115 & 22 \\
& C & Spastic bilateral & 1 & 0 & 12 & 140 & 31 \\
CP & D & Spastic bilateral & 2 & 0 & 15 & 155.4 & 46 \\
& E & Spastic unilateral & 2 & 1 & 7 & 116 & 32 \\
& F & Spastic unilateral & 2 & 0 & 10 & 138 & 38 \\
\hline
\end{tabular}

CP: cerebral palsy; ND; normally developing children; GMFCS: Gross Motor Function Classification Scale

$\mathrm{CP}$, and measured the of physical fitness of adult male $\mathrm{CP}$ subjects ${ }^{18)}$, their evaluations were performed using an arm ergometer. Therefore, their score does not reflect changes in fitness resulting from a mainly leg-based training program.

Timed walking tests may offer a less expensive, simpler, and safer alternative to laboratory testing of children with $\mathrm{CP}^{10,19)}$. Among such tests, the 6-min walk test (6MWT) has been shown to predict cardiorespiratory fitness in both healthy and severely disabled children, whether used with or without gas collection ${ }^{20,21)}$.

Novac et al. ${ }^{22)}$ systematically discussed the most effective and applicable interventions for children with CP. In their reports of the literature, the most recommended and applicable intervention was green light intervention, and they emphasized the importance of fitness training for aerobic fitness. Before children with CP perform aerobic fitness tests, their aerobic ability should be measured. However, previous studies have reported in lacked consistent results and utilized various measurement methods and environments. Thus, it is necessary to provide a precise method and measurement for base data to obtain accurate reference values. Accordingly, this preliminary study aimed to determine the cardiorespiratory endurance of children with $\mathrm{CP}$ using a case series study in order to provide the reference data required for interventions appropriate for South Korean CP sufferers, since aerobic ability evaluation and interventions for it for children with CP are not well recognized in South Korea.

\section{SUBJECTS AND METHODS}

Six children participated in this study. Four subjects $(3$ boys, 1 girl) had a diagnosis of bilateral or unilateral spastic $\mathrm{CP}$, and 2 subjects (1 boy, 1 girl) were children with normal development. Four children with CP GMFCS (Gross Motor Function Classification System) level I and II and two normally developing children (age: 7-15 years) were studied (Table 1). Subjects with CP were recruited from a Medical Center in Gyeonggi-do South. This study complied with the ethical prinsiples of the Declaration of Helsinki, and all the subjects and parents received explanations regarding the purpose and procedure of the study before voluntarily agreeing to take part. All parents signed an informed consent statement before the start of the measurements. Before testing, a medical examination was completed and anthropometric data were collected. The inclusion criteria were GMFCS levels I to II, uni- or bilateral spastic CP, age of 5-16 years, ability to walk continuously for $6 \mathrm{~min}$, and ability to provide informed consent. Potential subjects were excluded if they had received orthopedic surgery or neurosurgery and/or botulinum toxin injection within the previous 6 months, or had cardiac or respiratory conditions that could have been negatively affected by the proposed training. All the selected subjects were also free of intellectual problems that could have influenced their participation and/or motivation. Cycle ergometer testing was performed with calf supports (MOTOMed VIVA Cycle, Reek Medizinterchnik Gm BH, Betzenweiler, Germany). The cycle ergometer test served to familiarize and habituate the subjects, and it also allowed us to check whether a given subject needed to have his/her feet attached to the pedals by Velcro strapping ${ }^{23)}$. The concentration and volume of oxygen consumed $\left(\mathrm{VO}_{2}\right)$, peak respiratory exchange ratio (RER peak), and minute ventilation (VE) were measured simultaneously by portable metabolic measurement systems with preVent ${ }^{\mathrm{TM}}$ pneumotachs (MedGraphics VO2000-Medical Graphics, St. Paul, MN VO2000, USA). The ergometer test began with a 5-min warm up followed by 6-12 min of exercise with increasing intensity at a pedaling rate of $50 \mathrm{rpm}$ as paced by a metronome. Verbal encouragement was provided throughout the test to help each child achieve maximal effort. The subjects were also fitted with a neoprene face mask that could be used with the VO2000. A Polar HR strap was also fitted around the chest of the subjects (Polar Electro Oy, Kempele, Finland). Gas exchange and pulmonary ventilation values were recorded using the breath $\times$ breath mode with 20 -s average values printed during testing. The ergometer test was followed by 5 min of passive recovery.

The 6-min walk test was performed in the laboratory corridor between two lines set $20 \mathrm{~m}$ apart according to a standard procedure ${ }^{24)}$ under the supervision of the same physiotherapist. The subjects were instructed to walk as far as possible in $6 \mathrm{~min}$. The subjects received standardized and vigorous verbal encouragement, and they were advised of the distance covered and time remaining every $30 \mathrm{~s}$. All subjects performed, the cycle-ergometer test first, and the 6-min walking test was conducted on the next day to avoid fatigue effects.

\section{RESULTS}

The ages of the subjects were distributed as follows: two were aged 7 years, two were aged 12 years, one was aged 
Table 2. Subjects' peak cardiorespiratory responses to ergometry

\begin{tabular}{ccccccc}
\hline Type & Subjects & $\mathrm{VO}_{2}$ peak & RER peak & VE peak & HR peak & 6MWT \\
\hline \multirow{2}{*}{$\mathrm{ND}$} & $\mathrm{A}$ & 22.9 & 0.82 & 18.5 & 105 & 580 \\
& $\mathrm{~B}$ & 56.5 & 0.97 & 23.8 & 135 & 450 \\
& $\mathrm{C}$ & 25.9 & 1.36 & 25.3 & 145 & 578 \\
$\mathrm{CP}$ & $\mathrm{D}$ & 22.6 & 1.02 & 22.9 & 131 & 527 \\
& $\mathrm{E}$ & 44.5 & 0.87 & 32.5 & 129 & 390 \\
& $\mathrm{~F}$ & 57.4 & 0.97 & 59.5 & 147 & 560 \\
\hline
\end{tabular}

$\mathrm{VO}_{2}$ peak $(\mathrm{ml} / \mathrm{kg} / \mathrm{min})$ : peak oxygen uptake; RER peak: peak respiratory exchange ratio; VE peak $(1 /$ min): maximum ventilation per minute; HR peak (beats/min): peak heart rate; 6MWT (m): 6-min walk test

10 years, and one was aged 15 years; i.e, the youngest and oldest subjects were 7 and 15 years of age. Regarding the subjects GMFCS assessment, three were level II, and one was level I. Two normal children of 7 and 12 years age participated in this experiment to serve as controls for comparison with the children with CP. Table 1 shows the general characteristics of the subjects. The $\mathrm{VO}_{2}$ peak $(\mathrm{ml} / \mathrm{kg} / \mathrm{min})$ of child F (CP) was 57.4, which was the highest, and that of child $\mathrm{D}$ was 22.6 , which was the lowest. The two normal children, $\mathrm{A}$ and $\mathrm{B}$, had $\mathrm{VO}_{2}$ peaks $(\mathrm{ml} / \mathrm{kg} / \mathrm{min})$ of 22.9 and 56.5 , respectively. The RER peaks of all subjects were in the range of $0.82-1.36$. Overall, their scores were close to 1. In the 6MWT, child C (CP) walked $578 \mathrm{~m}$, which was the longest distance, and child E walked $390 \mathrm{~m}$, which was the shortest distance (Table 2). Furthermore, the comparison of $\mathrm{VO}_{2}$ peak between normal child A and child $\mathrm{C}(\mathrm{CP})$ showed that the former had a value of 22.9, which was lower than that of the latter. The comparison of $\mathrm{VO}_{2}$ peak between normal child B and child E (CP) showed that the latter had a value of 44.5 , which was lower than that of the former. The comparison of $6 \mathrm{MWT}$ between normal child $\mathrm{A}$ and child $\mathrm{C}$ (CP) and between normal child B and child E (CP) showed that the normal children walked further than the children with CP.

\section{DISCUSSION}

This preliminary study aimed to determine the cardiorespiratory endurance of children with $\mathrm{CP}$ using a case series study to provide the reference data required for interventions appropriate for South Korean CP sufferers, since aerobic ability evaluation and interventions for it for children with $\mathrm{CP}$ are not well recognized in South Korea.

Children with $\mathrm{CP}$ have lower $\mathrm{VO}_{2}$ peak values $(\mathrm{ml} / \mathrm{kg}$ / min) as well as shorter walking distances in set times than normal children. Numerous studies have reported the lower physical activities of children with CP in terms of aerobic abilities ${ }^{4,5,1725)}$, and some studies have reported that children and adolescents with $\mathrm{CP}$ have lower physical activity abilities than normal peers ${ }^{26}$. Verschuren et al. ${ }^{6}$ ) reported that comparisons with normative data sets suggest that adolescents with $\mathrm{CP}$ tend to participate in less structured and lower intensity physical activities than healthy adolescents.

Durstine et al. ${ }^{27}$ described a vicious circle in which persons with a chronic disease or disability experience less physical activity, which then leads to a cycle of deconditioning and further physical deterioration and reduction in activity. However, as seen in this study, the child with $\mathrm{CP}$ aged 7 (subject $\mathrm{E}$ ) had a lower $\mathrm{VO}_{2}$ peak value than the normally developing child (subject $\mathrm{B}$ ), and the child with $\mathrm{CP}$ aged 12 (subject $\mathrm{C}$ ) had a higher $\mathrm{VO}_{2}$ peak value than the normally developing child (subject A). Subject B (ND) had a lower $\mathrm{VO}_{2}$ peak than subject $\mathrm{E}(\mathrm{CP})$, consistent with the results of previous studies ${ }^{6,13)}$. One study $\left.{ }^{6}\right)$ reported that a child with $\mathrm{CP}$ had a $\mathrm{VO}_{2}$ peak value of $42 \mathrm{~mL} / \mathrm{kg} / \mathrm{min}$, which was close to our study result of $44.5 \mathrm{~mL} / \mathrm{kg} / \mathrm{min}$; however, the interpretation of the results of this previous are limited, because the subjects were aged from 7 to 17 years. With regard to the comparison of the results of subjects $\mathrm{A}$ and $\mathrm{C}$, it is necessary to determine the reason for the higher $\mathrm{VO}_{2}$ peak value in children with $\mathrm{CP}$ than in normal children, considering of various possibilities. A child with GMFCS level I can perform gross motor skills such as running and jumping and participate in physical and dynamic activities. In contrast, a child with CP at GMFCS level II cannot participate in physical and dynamic activities such as playground activities owing to his/her limited abilities. Despite examining only one case in this study, our results suggest children with $\mathrm{CP}$ who have small body mass and high functional level have even higher $\mathrm{VO}_{2}$ peak values than normal children. Nsenga et al. ${ }^{13)}$ reported that children with CP at GMFCS levels I and II can have cardiorespiratory endurance similar to that of normal children of similar ages.

Hoofwijk et al. ${ }^{5)}$ investigated ventilation in children with $\mathrm{CP}$ and healthy control groups. The former showed higher values (41.4) than the latter (33.6). This result was used as an explanation for the lower $\mathrm{VO}_{2}$ of children with $\mathrm{CP}$. The present study found comparable values for children and adolescents with $\mathrm{CP}$ and normally developing subjects. The ventilation peak (VEpeak) value for child $\mathrm{C}(\mathrm{CP})$ was higher (25.3) than that (18.5) of child A (ND). Similarly, the child E (CP) showed a higher value (32.5) than that (23.8) of child $\mathrm{B}$ (ND). Therefore, these results support the explanation of Hoofwijk et $\mathrm{al}^{5)}$.

The 6MWT was used to measure the functional walking capacity. The total distance walked was recorded as the 6MWT distance. The distance walked strongly correlated with the $6 \mathrm{MWT} \mathrm{VO}_{2}$ peak $(r=.948)$ and was related more modestly to the cycle-ergometer $\mathrm{VO}_{2}$ peak $(r=0.625)^{19}$. In this study, $\mathrm{VO}_{2}$ was not collected while performing the 
6MWT. However, the results of the present study show that children with $\mathrm{CP}(\mathrm{C}$ and $\mathrm{E})$ walked shorter distances than normal children (A and B). Nsenga et al. ${ }^{19)}$ reported that the 6MWT distance increased after aerobic training, showing a correlation between the cardiorespiratory capacity and $6 \mathrm{MWT}$ distance. Although a previous study suggested there is no significant correlation between the ergometer $\mathrm{VO}_{2}$ peak and 6MWT distance, Maanum et al. ${ }^{28)}$ reported that the 6MWT distance was a significant predictor of cardiorespiratory capacity for children with spastic $\mathrm{CP}$.

Two children with CP showed RER $>1.0$. This finding suggests that many children with $\mathrm{CP}$ do not produce maximal effort. Peak RER is generally used as a secondary criterion for maximal effort; however, large individual variations may be present depending on the test modes and protocols ${ }^{29)}$. The average peak RER values in the present study $(0.87-1.36)$ were comparable to the average values reported in previous studies of children with CP (0.9-1.15), and most studies have reported a peak HR of $190 \mathrm{bpm}^{4,30}$. These results does not support the finding that the children did not produce their maximal effort because of the lower peak HR values. However, the present study conducted ergometer tests and not treadmill tests; furthermore, there was an age difference among the subjects.

Thus far, most studies of children with $\mathrm{CP}$ have focused on cycle ergometer or treadmill walking tests ${ }^{6,8-10)}$, seeking to verified the effectiveness of these tests ${ }^{12,13-15,17)}$. However, the available literature on the cardio-respiratory capacity of children with $\mathrm{CP}$ focuses on treadmill walking rather than cycle ergometry. Treadmill tests have both supporters and critics. Verschuren et al. ${ }^{7}$ noted that treadmill protocols such as the Bruce and Balke tests are not appropriate for children with CP. Furthermore, treadmill testing is difficult for many children with $\mathrm{CP}$ because they suffer from severe balance issues ${ }^{31)}$. It is difficult to compare the children from all studies that have provided information about $\mathrm{VO}_{2}$ peak for children and adolescents with CP. Although many studies have recognized the importance of fitness for maintaining aerobic capacity, it is not easy to conduct aerobic tests with children with CP owing to the limitations described in the studies cited above. Among studies with a high evidence level, the accuracy of the results may not be that high owing to the use of arm ergometry rather than a test of the lower extremities. Other studies include a case study ${ }^{15}$ ) with a low evidence level and studies with a small number of subjects ${ }^{12-14)}$. Accordingly, more evidence and data that can be used as a reference to provide fitness programs for school children with CP are needed in the future. This study aimed to determine the cardiorespiratory endurance of children with $\mathrm{CP}$ using a case series study in order to provide the reference data required for interventions appropriate for South Korean CP sufferers, since aerobic ability evaluation and interventions for it for children with CP are not well recognized in South Korea. Despite success in the study aims, the results should be interpreted with care, owing to the small number of participating subjects.

In conclusion, this case report reports cardiorespiratory parameter values that are similar to those that have been reported previously. Fitness training for aerobic fitness is an important intervention method for children with CP. Accord- ingly, it is necessary to provide evidence of cardiorespiratory fitness levels for children with $\mathrm{CP}$ when such fitness programs are conducted. Furthermore, it is necessary to provide precise methods and measurements for base data in every assessment to obtain accurate reference values. In this regard, our study will provide information about $\mathrm{VO}_{2}$ peak values for an aerobic-fitness-related study conducted with children with $\mathrm{CP}$ in the future.

\section{REFERENCES}

1) Rosenbaum P, Paneth N, Leviton A, et al.: A report: the definition and classification of cerebral palsy April 2006. Dev Med Child Neurol Suppl, 2007, 109: 8-14. [Medline]

2) van den Berg-Emons HJ, Saris WH, de Barbanson DC, et al.: Daily physical activity of schoolchildren with spastic diplegia and of healthy control subjects. J Pediatr, 1995, 127: 578-584. [Medline] [CrossRef]

3) Rimmer JH: Physical fitness levels of persons with cerebral palsy. Dev Med Child Neurol, 2001, 43: 208-212. [Medline] [CrossRef]

4) Maltais DB, Pierrynowski MR, Galea VA, et al.: Physical activity level is associated with the $\mathrm{O}_{2}$ cost of walking in cerebral palsy. Med Sci Sports Exerc, 2005, 37: 347-353. [Medline] [CrossRef]

5) Hoofwijk M, Unnithan V, Bar-Or O: Maximal treadmill performance of children with cerebral palsy. Pediatr Exerc Sci, 1995, 7: 305-313.

6) Verschuren O, Takken T: Aerobic capacity in children and adolescents with cerebral palsy. Res Dev Disabil, 2010, 31: 1352-1357. [Medline] [CrossRef]

7) Verschuren O, Takken T, Ketelaar M, et al.: Reliability and validity of data for 2 newly developed shuttle run tests in children with cerebral palsy. Phys Ther, 2006, 86: 1107-1117. [Medline]

8) Pirpiris M, Wilkinson AJ, Rodda J, et al.: Walking speed in children and young adults with neuromuscular disease: comparison between two assessment methods. J Pediatr Orthop, 2003, 23: 302-307. [Medline] [CrossRef]

9) Keefer DJ, Tseh W, Caputo JL, et al.: Within- and between-day stability of treadmill walking VO2 in children with hemiplegic cerebral palsy, stability of walking VO2 in children with CP. Gait Posture, 2005, 21: 80-84. [Medline]

10) Kerr C, McDowell BC, Cosgrove A: Oxygen cost versus a 1-minute walk test in a population of children with bilateral spastic cerebral palsy. J Pediatr Orthop, 2007, 27: 283-287. [Medline] [CrossRef]

11) Provost B, Dieruf K, Burtner PA, et al.: Endurance and gait in children with cerebral palsy after intensive body weight-supported treadmill training. Pediatr Phys Ther, 2007, 19: 2-10. [Medline] [CrossRef]

12) Williams H, Pountney $T$ : Effects of a static bicycling programme on the functional ability of young people with cerebral palsy who are non-ambulant. Dev Med Child Neurol, 2007, 49: 522-527. [Medline] [CrossRef]

13) Nsenga AL, Shephard RJ, Ahmaidi S: Aerobic training in children with cerebral palsy. Int J Sports Med, 2013, 34: 533-537. [Medline]

14) Tobimatsu $Y$, Nakamura R, Kusano $S$, et al.: Cardiorespiratory endurance in people with cerebral palsy measured using an arm ergometer. Arch Phys Med Rehabil, 1998, 79: 991-993. [Medline] [CrossRef]

15) Siebert KL, DeMuth SK, Knutson LM, et al.: Stationary cycling and children with cerebral palsy: case reports for two participants. Phys Occup Ther Pediatr, 2010, 30: 125-138. [Medline] [CrossRef]

16) Demuth SK, Knutson LM, Fowler EG: The PEDALS stationary cycling intervention and health-related quality of life in children with cerebral palsy: a randomized controlled trial. Dev Med Child Neurol, 2012, 54: 654-661. [Medline] [CrossRef]

17) Unnithan VB, Katsimanis G, Evangelinou C, et al.: Effect of strength and aerobic training in children with cerebral palsy. Med Sci Sports Exerc, 2007, 39: 1902-1909. [Medline] [CrossRef]

18) Kusano S, Iwasaki Y, Tobimatsu $\mathrm{Y}$, et al.: Cardiorespiratory endurance and work efficiency of people with cerebral palsy measured using an arm ergometer. J Phys Ther Sci, 2001, 13: 49-52. [CrossRef]

19) Nsenga Leunkeu A, Shephard RJ, Ahmaidi S: Six-minute walk test in children with cerebral palsy gross motor function classification system levels I and II: reproducibility, validity, and training effects. Arch Phys Med Rehabil, 2012, 93: 2333-2339. [Medline] [CrossRef]

20) Nixon PA, Joswiak ML, Fricker FJ: A six-minute walk test for assessing exercise tolerance in severely ill children. J Pediatr, 1996, 129: 362-366. [Medline] [CrossRef]

21) Li AM, Yin J, Yu CC, et al.: The six-minute walk test in healthy chil- 
dren: reliability and validity. Eur Respir J, 2005, 25: 1057-1060. [Medline] [CrossRef]

22) Novak I, McIntyre S, Morgan C, et al.: A systematic review of interventions for children with cerebral palsy: state of the evidence. Dev Med Child Neurol, 2013, 55: 885-910. [Medline] [CrossRef]

23) Nsenga Leunken A, Gayda M, Nigam A, et al.: Cardiopulmonary exercise data during quadriceps isometric contraction sustained fatigue in children with cerebral palsy. Isokinet Exerc Sci, 2009, 17: 27-33.

24) ATS Committee on Proficiency Standards for Clinical Pulmonary Function Laboratories: ATS statement: guidelines for the six-minute walk test. Am J Respir Crit Care Med, 2002, 166: 111-117. [Medline] [CrossRef]

25) van Eck M, Dallmeijer AJ, Beckerman H, et al.: Physical activity level and related factors in adolescents with cerebral palsy. Pediatr Exerc Sci, 2008, 20: 95-106. [Medline]

26) Maher CA, Williams MT, Olds T, et al.: Physical and sedentary activity in adolescents with cerebral palsy. Dev Med Child Neurol, 2007, 49: 450-
457. [Medline] [CrossRef]

27) Durstine JL, Painter P, Franklin BA, et al.: Physical activity for the chronically ill and disabled. Sports Med, 2000, 30: 207-219. [Medline] [CrossRef]

28) Maanum G, Jahnsen R, Frøslie KF, et al.: Walking ability and predictors of performance on the 6-minute walk test in adults with spastic cerebral palsy. Dev Med Child Neurol, 2010, 52: e126-e132. [Medline] [CrossRef] 29) Armstrong N, Welsman JR: Aerobic fitness. Pediatric exercise science and medicine. Oxford: Oxford University Press, 2008.

30) Dallmeijer AJ, Brehm MA: Physical strain of comfortable walking in children with mild cerebral palsy. Disabil Rehabil, 2011, 33: 1351-1357. [Medline] [CrossRef]

31) Potter CR, Unnithan VB: Interpretation and implementation of oxygen uptake kinetics studies in children with spastic cerebral palsy. Dev Med Child Neurol, 2005, 47: 353-357. [Medline] [CrossRef] 